\title{
Research on Evaluation of Customer Experience of B2C E- commerce Logistics Enterprises
}

\author{
Yilei Pei ${ }^{1, a}$, Wanxin Xue ${ }^{1, b}$, Dandan $\mathrm{Li}^{1, c}$, Yong Su${ }^{2, d}$ \\ ${ }^{1}$ Department of Information Management and E-commerce, Beijing Union University, Beijing, \\ 100101, China \\ ${ }^{2} 95997$ Unit of PLA, Beijing, 100076, China \\ aemail: peiyilei@126.com, bemail:xuewanxin@126.com, lidandanhdj@163.com, \\ dsudoo@163.com
}

Keywords: B2C e-commerce logistics enterprises; customer experience; fuzzy comprehensive evaluation

\begin{abstract}
With the rapid development of E-commerce, more and more enterprises attach great importance to customer experience, and B2C E-commerce logistics enterprises make no exception. The good customer experience can promote consumer s' perception of the service level of ECommerce logistics enterprises. This paper establishes index system customer experience of B2C E-commerce logistics enterprises, uses analytic hierarchy process to determine the weight of each level index, establishes the fuzzy comprehensive evaluation model, finally the case study shows that it is reasonable and credible to evaluate customer experience of $\mathrm{B} 2 \mathrm{C}$ E-commerce logistics enterprises with analytic hierarchy process and fuzzy comprehensive evaluation.
\end{abstract}

\section{Introduction}

With the rapid development of Internet technology and e-commerce, more and more B2C Ecommerce logistics enterprises attach great importance to online customer experience, because more customers complete the purchasing, ordering, and even after-sales service of goods through the network. But now China's e-commerce logistics services are mainly labor-intensive services and the utilization of basic facilities is low, so it is difficult to meet the growing demand for online consumers. Therefore, it is urgent for China's e-commerce logistics enterprises to improve the service level of the distribution link of physical commodities.

Customers attach importance to obtaining the special feeling in accordance with the personality, taste preferences and values in the process of information collection and evaluation, when they make the purchase decision, namely the experience. The good customer experience can promote consumers' perception of the service level of e-commerce logistics enterprises, and then promote service purchase intention and service purchase behavior of consumers .

Hsuan (2011) proposes customer experience is the important factor to promote purchase behaviors, but under the environment of E-Commerce customer experience has not been fully studied [1]. At present, most of researches on customer experience focus on the limited types of service industry, which is only concerned with the phenomenon of customer experience in the physical service environment The phenomenon of the customer experience of logistics service in the virtual environment is lack of scientific research.

In addition, conducting research on the dimensions of customer experience of $\mathrm{B} 2 \mathrm{C}$ e-commerce logistics enterprise and evaluating customer experience of B2C E-commerce logistics enterprises are issues in the lack of research in the current theoretical research and management practices, doing that will evaluate the customer experience of B2C e-commerce logistics enterprises objectively, understand and predict customer service purchase intention of B2C e-commerce logistics enterprise better, and promote the healthy and rapid growth of $\mathrm{B} 2 \mathrm{C}$ E-commerce logistics enterprises. 


\section{The Index System of Customer Experience of B2C E-commerce Logistics Enterprises}

\section{Literature Review}

Wenfei Wei (2013) proposes E-commerce logistics is a series of transportation, storage, handling, packaging, circulation processing, information processing and distribution activities carried out under the environment of network and information technology support, which requires activities match with the information flow and capital flow of electronic and network level under the environment of E-commerce, and the logistics objects include virtual goods (or services) and physical goods.

Kohler (2011), Rose (2012) propose in view of the nature of Web2.0 technology, in the virtual environment, customers and retailers co-create experience.

According to the researches above, this paper defines customer experience of $\mathrm{B} 2 \mathrm{C}$ Ecommerce logistics enterprises as the process in which customers obtain the special feeling, form cognition and evaluation, thus affect the meeting of psychological demands and decision making through a set of logistics service environments and interactive logistics service that E-Commerce logistics websites and operators provide.

\section{Establishment of Evaluation Index System}

In 1988, PZB propose the SERVQUAL model, and developed a set of service quality scale which is composed of tangibility, reliability, assurance, responsiveness and empathy five dimensions, based on the background of banking and retailing services industries. For B2C ecommerce logistics enterprise customers, service quality experience is an important dimension of customer experience.

Hongli Guo and Jing Wang (2013) uses website usefulness and website ease of use two dimensions, when building B2C customer experience model based on the TAM model; website usefulness is described by information quality, service level and the degree of attention to personal needs three variables; website ease of use is described by learning cost, the degree of relative convenience and website system quality three variables. Yuanyuan Cao (2013) identifies website navigation function, search function, operational flexibility, simplicity of operational process and other functions, and aesthetics, professionality, characteristics of website design affect customer experience[2]. Guoqing Guo's (2012) empirical research shows that the communication dimension of website interactivity is the key to improve consumer experience value and satisfaction. Therefore, customer experience of $\mathrm{B} 2 \mathrm{C}$ e-commerce logistics enterprises contains the usefulness, ease of use and interactive experience of the website.

Datian $\mathrm{Bi}(2014)$ measures customer experience of B2C e-commerce enterprises from perceptual experience, emotional experience and trust experience three dimensions. Danyang Huang(2014) measure customer shopping experience of $\mathrm{B} 2 \mathrm{C}$ websites from initial product user experience, information product user experience and product platform user experience three dimensions.

According to the researches above, this paper design evaluation index system, as shown in Table 1. 
Table 1. Evaluation index system of Customer Experience of B2C E-commerce Logistics Enterprises

\begin{tabular}{|c|c|c|}
\hline One-level indexes & Two-level indexes & Interpretation of indicators \\
\hline \multirow{5}{*}{ website experience } & usefulness & $\begin{array}{l}\text { website service quality and information } \\
\text { quality }\end{array}$ \\
\hline & ease of use & $\begin{array}{l}\text { website function quality, website design } \\
\text { quality, the degree of relative } \\
\text { convenience }\end{array}$ \\
\hline & interactivity & $\begin{array}{l}\text { mutual communication and mutual } \\
\text { influence between } \\
\text { customers }\end{array}$ \\
\hline & service tangibility & $\begin{array}{l}\text { The actual facilities, equipment and } \\
\text { service personnel's appearance of B2C e- } \\
\text { commerce logistics enterprise }\end{array}$ \\
\hline & service reliability & $\begin{array}{l}\mathrm{B} 2 \mathrm{C} \text { e-commerce logistics enterprises can } \\
\text { perform the service commitment reliably } \\
\text { and accurately }\end{array}$ \\
\hline \multirow[t]{3}{*}{ service experience } & service assurance & $\begin{array}{l}\text { employees' knowledge, etiquette and the } \\
\text { ability to express confidence and } \\
\text { credibility in B2C e-commerce logistics } \\
\text { enterprises }\end{array}$ \\
\hline & service responsiveness & $\begin{array}{l}\mathrm{B} 2 \mathrm{C} \text { e-commerce logistics enterprises } \\
\text { help customers and improve service } \\
\text { levels rapidly }\end{array}$ \\
\hline & service empathy & $\begin{array}{l}\text { B2C e-commerce logistics enterprises } \\
\text { care about customers and provide } \\
\text { customers with personalized service }\end{array}$ \\
\hline \multirow[t]{3}{*}{$\begin{array}{l}\text { information } \\
\text { experience }\end{array}$} & information timeliness & $\begin{array}{l}\mathrm{B} 2 \mathrm{C} \text { e-commerce logistics enterprises } \\
\text { provide customers with timely and } \\
\text { convenient logistics information }\end{array}$ \\
\hline & information reliability & $\begin{array}{l}\mathrm{B} 2 \mathrm{C} \text { e-commerce logistics enterprises } \\
\text { provide customers with accurate and } \\
\text { reliable logistics information }\end{array}$ \\
\hline & information security & $\begin{array}{l}\mathrm{B} 2 \mathrm{C} \text { e-commerce logistics enterprises } \\
\text { provide customers with safe and reliable } \\
\text { logistics information }\end{array}$ \\
\hline
\end{tabular}

\section{Fuzzy Comprehensive Evaluation}

\section{Establishment of Factor Set and Evaluation Set}

Factor set is made up of elements that affect the judgment objects. It can be commonly expressed as follows: $U=\left\{U_{1}, U_{2}, \ldots, U_{n}\right\}$.

According the analysis above, there are 15 single factors affecting $\mathrm{B} 2 \mathrm{C}$ e-commerce logistics enterprises, and they can be divided into two tiers. The factor set can be established as $U=\left\{U_{1}, U_{2}, U_{3}\right\}$, and the single-factor sets are $U_{1}=\left\{u_{11}, u_{12}, u_{13}\right\}, U_{2}=\left\{u_{21}, u_{22}, u_{23}, u_{24}, u_{25}\right\}$, $U_{3}=\left\{u_{31}, u_{32}, u_{33}\right\}$.

Evaluation set is made of all kinds of total judgment results given by judges as elements. It can be expressed as $V$, namely, $V=\left\{V_{1}, V_{2}, \ldots, V_{m}\right\}$.

The evaluation set $\mathrm{V}$ of $\mathrm{B} 2 \mathrm{C}$ e-commerce logistics enterprises can be established with five evaluation results: excellent, good, moderate, common and bad. 


\section{Establishment of Weight Set}

Every factor has different importance degree. To reflect the differences, every factor $U_{i}$ is endowed with corresponding weight $w_{i}$. And the set $W=\left(w_{1}, w_{2}, \cdots, w_{n}\right)$ which consists of weights is called factor weight set.

Establishment of the multi-level evaluation model First, complex problems break down into several elements and different elements are divided into several groups. Then we establish a multilevel evaluation model based on the group status.

Establishment of the comparison judgment matrix Membership between the up-down hierarchy members is determined after we establish the multi-level evaluation model. We draw the pairwise comparison between elements in each hierarchy of the multi-level model for the correlative up-level element, and then establish a series of judgment matrixes as follows:

$$
A-B_{i}=\left[\begin{array}{cccc}
b_{11} & b_{12} & \cdots & b_{1 n} \\
b_{21} & b_{22} & \cdots & b_{2 n} \\
\cdots & \cdots & \ddots & \cdots \\
b_{n 1} & b_{n 2} & \cdots & b_{n n}
\end{array}\right]
$$

In the formulation, $b_{i j}>0, b_{i j}=1 / b_{j i}, b_{i i}=1 . b_{i j}$ stands for the importance proportion scale of $B_{i}$ and $B_{j}$ for the correlative up-level element $A$. When drawing the pairwise comparison between elements, one-to-nine scale method is usually adopted as shown in Table 2.

Table 2: The definition of scale method

\begin{tabular}{cl}
\hline Scale & Definition description \\
\hline 1 & The equal importance of two elements comparison. \\
3 & The former is a little more important than the latter. \\
5 & The former is obviously more important than the latter. \\
7 & The former is mightily more important than the latter. \\
9 & The former is extremely more important than the latter. \\
$2,4,6,8$ & The intermediate values of adjacent judgments above.
\end{tabular}

This paper uses characteristic root method to compute collating weight vector. We suppose that the max characteristic root of judgment matrix is $\lambda_{\max }$, and the corresponding characteristic vector is $\mathrm{W}$. The methods of $\mathrm{W}$ and $\lambda_{\max }$ are as follows:

i) Multiply elements of $A-B_{i}$ according to line;

ii) Extract gained products for $n$ times;

iii) Normalize the root vector and get the collating weight vector $\mathrm{W}$;

$$
\begin{aligned}
& w_{i}=\sqrt[n]{\prod_{j=1}^{n} b_{i j}} / \sum_{i=1}^{n} \sqrt[n]{\prod_{j=1}^{n} b_{i j}}(i=1, \cdots, n) \\
& \lambda_{\max }=\sum_{i=1}^{n} \frac{\sum_{i=1}^{n} b_{i j} w_{i}}{n w_{i}}(i=1, \cdots, n)
\end{aligned}
$$

Consistency check To make sure that the decision-making process is scientific, consistency check of $\lambda_{\max }$ is necessary. Checking process is as following:

i) The calculation of coincidence index CICI $=\left(\lambda_{\max }-n\right) /(n-1)$

ii) The calculation of coincidence rate $\mathrm{CR} C R=C I / R I$

$\mathrm{RI}$ is random coincidence index. When $\mathrm{CR}<0.1$, we consider that judgment matrix has a good consistency, or else we should adjust the values of elements in judgment matrix.

The calculation of combination weight of each level element To get the weights of all elements of each level for the overall objective, it is necessary to judge the value of CR. If $C R \geq 0.1$, we should assemble the calculation results of the third step properly and check the total judgment consistency. 
We do this step basipetally. The final results indicate the relative weight of decision-making priority sequence and the judgment consistency check of the whole hierarchical model.

\section{Fuzzy Evaluation}

First, experts evaluate from the single element of factor set $U$ and determine the degree of membership that the evaluation objects rely on the elements of factor set. Then, we establish the total evaluation matrix consisting of evaluation sets of $n$ elements. It is usually expressed as R.

After we get values of $\mathrm{W}$ and $\mathrm{R}$, we can do fuzzy mapping to have a comprehensive judgment. The mathematical model of fuzzy comprehensive evaluation is shown as: $B=W \cdot R$

\section{Application Example Analysis}

We have a fuzzy comprehensive evaluation of customer experience of B2C e-commerce logistics enterprises, based on theoretical study and combining the practical needs of customers in certain B2C e-commerce logistics enterprise. The model is as shown in Fig 1.

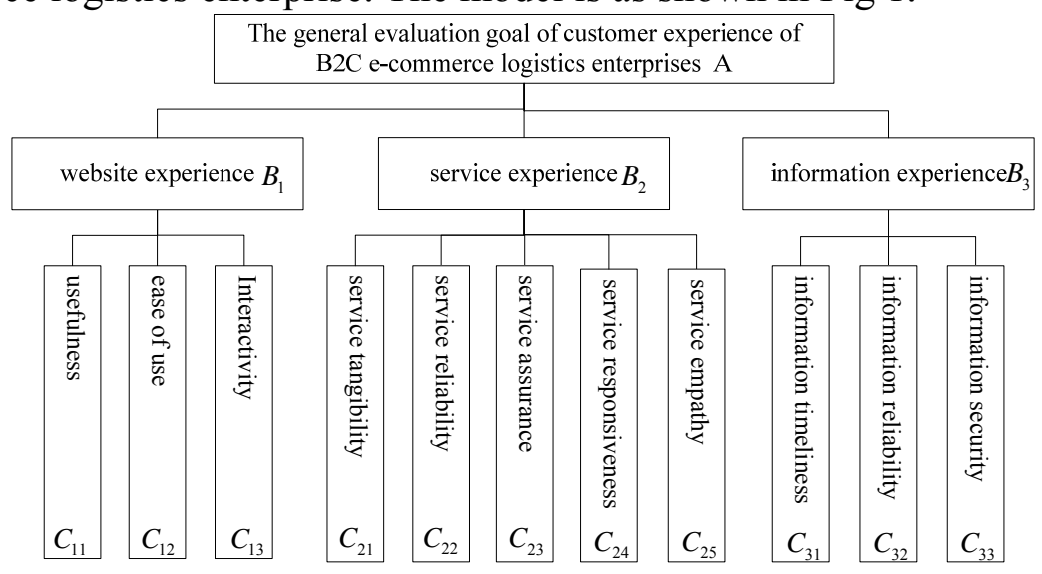

Fig.1. Step-down hierarchical model of network growth capabilities of high-tech small and microsized enterprises

According to Fig .1 above, we structure the judgment matrix $A-B_{i}$.

Similarly, we can establish the judgment matrix of C-level elements for correlative B-level elements.

Based on Formulation (1) and (2), we calculate and get: $\lambda_{\max }=5.0680$,

$W_{B}=(0.1365,0.2385,0.6250) . \mathrm{W}$ is the weight set of B-level elements for the general goal.

Based on Formulation (3), we calculate and get: $\mathrm{CI}=0.0170$. When $\mathrm{n}=3, \mathrm{RI}=0.58$.

Based on Formulation (4), we calculate and get: $\mathrm{CR}=0.0158<0.10$.

This indicates that the judgment matrix has a satisfying consistency.

Similarly, we can also calculate all weights of evaluation indexes of customer experience of this B2C e-commerce logistics enterprise.

According to all weights of evaluation indexes, we can calculate and get combination weight: $\mathrm{W}=(0.0959,0.2706,0.1110,0.1263,0.0114,0.0599,0.0753,0.1881,0.0183,0.0332,0.0100)$.

Evaluating factor set $U$ is made up of eleven factors influencing customer experience of this B2C e-commerce logistics enterprise. Evaluation set $\mathrm{V}$ is established with five evaluation results for the factors: excellent, good, moderate, common and bad.

According to experts' test data of customer experience of this B2C e-commerce logistics enterprise, we establish estimation matrix.

Based on Formulation (5), we can calculate: $B=(0.1288,0.4274,0.3773,0.0665,0)$. 
According to the principle of maximum degree of membership, the maximum degree $\max \left(b_{i}\right)=0.4274$, which shows that customer experience of this $\mathrm{B} 2 \mathrm{C}$ e-commerce logistics enterprise is the second level, namely, that is good.

\section{Conclusions}

This paper adopts the method of analytic hierarchy process and fuzzy evaluation to establish the fuzzy comprehensive evaluation model, in order to avoid the effect of individual subjective judgment and favoritism on the result of customer experience of $\mathrm{B} 2 \mathrm{C}$ e-commerce logistics enterprises.

According to the results, fuzzy comprehensive evaluation is a reasonable and feasible method to evaluate customer experience of B2C e-commerce logistics enterprises, and it can be used widely in customer experience of $\mathrm{B} 2 \mathrm{C}$ e-commerce logistics enterprises.

\section{Acknowledgement}

In this paper, the research was sponsored by Beijing Higher Education Young Elite Teacher Project(No.YETP1761).

\section{References}

[1] Hsuan Yu Hsua. Understanding Customer Experiences in Online Blog Environments [J]. International Journal of Information Management, 2011, (31): 510-523.

[2] F. Lemke, M. Clark, H. Wilson, Customer Experience Quality: An Exploration in Business and Consumer Contexts Using Repertory Grid Technique [J], J. Acad. Mark. Sci, 2011, 39(6): 846-869.

[3] S. Rose, M. Clarck, P. Samouel, N. Hair, Online Customer Experience in E-retailing: An Empirical Model of Antecedents and Outcomes [J], J. Retail, 2012, 88(2): 308-322.

[4] Guo Hongli, Wang Jing. The Study of B2C Customer Experience Model Based on Tam Model, Science and Technology Management Research [J]h, 2013, (19): 184-188.

[5] Cao Yuanyuan, Zhang Jiantong. E-commerce Customer Experience Evaluation Research Based on Factor Analysis and Synthetic Fuzzy Method [J]. Shanghai Management Science, 2012, 35(2): 34-38.

[6]Guo Guo-qing, Li Guang-ming, The Influence of Interactivity of Online Shopping on Consumers' Experiential Value and Satisfaction [J], China Business and Market, 2012, (2): 112-118. 